\title{
Implementing Performance Measurement Systems in Local Governments: Moving from the "How" to the "Why"
}

\author{
Tommaso Agasisti, Deborah Agostino and Mara Soncin ${ }^{1}$ \\ Department of Management, Economics and Industrial Engineering, Politecnico di Milano, \\ Milan, Italy
}

This is a post-peer-review, pre-copyedit version of an article published in Public Performance \& Management Review. The final authenticated version is available online at https://doi.org/10.1080/15309576.2019.1700806

\begin{abstract}
.
This paper examines how Performance Measurement Systems (PMSs) are implemented in local governments where the initial context is defined by equivalent external pressures and professional expertise, in order to address the question of "why" PMS implementation patterns differ from one setting to another. The study explored the reasons behind these different patterns in a context where local governments responsible for providing a local service implemented a PMS with the direct support of professional experts, and thereby it contributes to the extant literature in the field of PMS implementation. In order to achieve this purpose, the investigation analyzed three local governments (municipalities) that were required to implement a PMS because of external legislation requirements rather than by choice and is based upon a participatory case study approach involving interviews, observations and secondary data sources. Research was conducted through the theoretical lens of Old Institutional Economics to identify three PMS implementation patterns, here called formal compliance, shared vision and technical oligarchy. The role played by three factors, power, communication and an inclination to learn, is discussed in the results, as these three factors in particular may help to explain the heterogeneity in the implementation patterns observed.
\end{abstract}

\section{Keywords.}

Performance Measurement System, local government, municipalities, public services, implementation process

\footnotetext{
${ }^{1}$ Mara Soncin, Department of Management, Economics and Industrial Engineering, Politecnico di Milano, via Raffaele Lambruschini 4/b, Milan, Italy, email: mara.soncin@ polimi.it
} 


\section{Introduction}

This study addresses the question of "why" the Performance Measurement System (PMS) implementation patterns differ among local governments where there are the same external normative pressures to introduce a PMS. Current literature on PMS implementation focuses mainly on "how" a PMS is implemented, providing evidence on the way organizational change is managed and on the organizational roles and micro-dynamics involved (Poister and Streib 1999; Camilleri and Van Der Heijden, 2007; Johansson and Siverbo 2009; Keerasuntonpong and Cordery, 2018). These available studies have increased our understanding of the possible PMS implementation patterns and usage of these systems, which can range from rational to ritualistic (Agostino and Arnaboldi, 2017). Research on the topic has prompted a lively debate into the decoupling of externally imposed PMSs from the practices that are actually in use (van Helden et al., 2008; Yetano, 2013; Akbar et al., 2015; Goddard et al., 2016; Barbato and Turri, 2017).

Relatively limited attention has, however, addressed "why" we see different PMS implementation patterns emerging. The previous studies that tackled this issue were mainly concerned with the common determinants (Julnes and Holzer, 2001; Hoontis and Kim, 2012; Yetano, 2013; Taylor, 2014) and only rarely examined the heterogeneity across cases. This study, thus, provides new evidence by exploring the underpinning reasons relating to why this heterogeneity in implementation emerges within a setting where PMSs were implemented with help from experts, who somehow act as disruptors. Hence, the distinctive feature of this paper is that it studies the process of implementing a PMS with the help and technical knowledge of professional experts, and thereby offers a different perspective on the topic. Whilst the lack of resources is known to have a negative effect on the implementation process (Julnes and Holzer, 2001; Hoontis and Kim, 2012; Kroll, 2015), in our setting, the results are analyzed net of any financial or technical shortcoming, as these resources are factored into the project. By ruling out 
any financial or technical barriers and including a valuable factor in the form of the role played by professional experts, we are contributing to the debate on the reasons behind the heterogeneity within PMS implementation processes. Differently stated, our study addresses the following question: Why do different PMS implementation patterns emerge in similar contexts where the same PMS is imposed externally, and equivalent professional support is available during its implementation?

This study is based upon a participatory case study (Reilly, 2010) concerning three Italian municipalities where the authors were involved as professional experts during the implementation of an the PMS. The aim of the project was to strengthen the PMS culture within these local governments (as required under the legislation) by leveraging on benchmarking and providing technical expertise during the implementation phase. The case study was carried out over fifteen months in 2016 and 2017. The researchers attended plenary and ad hoc meetings, as well as being in direct weekly contact with the administrative staff working on the implementation project within the three municipalities. The different PMS implementation patterns that emerged were examined through the theoretical lens of Old Institutional Economics (Burns and Scapens, 2000), which states that internal organizational dynamics play a role in the PMS implementation process. In this case, the heterogeneity in implementation patterns was investigated by exploring three intra-organizational dynamics, specifically the dynamics of power, communication and an inclination to learn.

The case studies gave rise to three implementation patterns, which have been called formal compliance, shared vision and technical oligarchy implementations. Our investigation into the "why" behind these patterns contributes to the discussion on the importance of power dynamics, communication and inclination to learn, in terms of how they can influence the PMS implementation process. When power and communication are centralized in the hands of senior management and staff show no inclination to learn, the outcome appears to be a formally 
compliant implementation. On the contrary, a high inclination to learn - even when communication is scarce and the power dynamics in play are relatively assertive - seems to favor a more engaged kind of PMS implementation.

This study contributes to the literature on PMS in local governments along three main lines. Firstly, by considering internal organizational dynamics as the main determinant of PMS implementation, the study underlines the importance of moving from "how" different PMS implementation patterns develop to "why" these patterns occur. Secondly, this study enhances the debate on the role played by professional experts and internal organizational dynamics within the context of PMS implementation. Finally, this study offers some policy-level considerations with its critical discussion into the effects of implementing a PMS within local governments where there is overwhelming pressure for external accountability, as is the case in Italy.

These arguments are presented in this paper, which is structured as follows. The related literature on PMS implementation is first outlined, alongside the theoretical framework and the description of the methodology. After that, the research setting is introduced, and the results are then presented. Finally, the paper sets out some conclusions about "why" there were different PMS patterns.

\section{Related literature}

Academics and practitioners have been studying the implementation and adoption of PMSs within local government ever since the introduction of the New Public Management paradigm in the early 1990s (Kloot and Martin, 2000; Pollitt 2001; van Thiel and Leeuw, 2002; van Helden et al., 2008). Notwithstanding the significant bulk of literature on this topic, PMS in local government continues to attract the attention of public sector scholars, who have underlined the paradoxes in the approach and the controversial position of endorsing the use of performance measures - traditionally developed for private companies - in the public sector 
(van Thiel and Leeuw, 2002; Hoontis and Kim, 2012; Ammons, 2013; Schleicher et al., 2018; Song and Meier, 2018).

More specifically, earlier literature has provided several contributions on the implementation of PMSs in local governments, where the focus was on the "what" and the "how".

Research dealing with the "what" has tackled measurement systems from the technical design angle, examining the indicators, target and performance drivers involved in developing a PMS. It has been noted that specific issues linked to measuring performance in the public sector are intrinsic to organizations where numerous people, each with their sphere of action, are involved in the overall PMS process (Propper and Wilson, 2003; Ammons, 2013). De Bruijn (2003) suggested three principles for successfully designing a PMS, namely the interaction between management and external professional/s, variety in the indicators defined and the ability to reflect the dynamism of an organization. Behn (2003) connected the reasons for measuring performance to the measures that are used in the process. For instance, if the purpose of conducting these measurements is to generate organizational learning, then the system requires measures that provide disaggregated information on the particular aspect/s under investigation, while measuring performance against budget requires defining the efficiency of the activities targeted.

The "how" places attention on the way in which a previously designed PMS system (the "what") is put into practice. This stream of literature is concerned with the organizational roles, risks and cultural issues connected to translating a PMS into everyday usage (Poister and Streib 1999; Sanderson 2001; Fryer et al. 2009; Johansson and Siverbo 2009; Yetano, 2013; Keerasuntonpong and Cordery, 2018). These aspects were discussed in studies that acknowledge the risk of decoupling the formal systems adopted from the practices actually in use (Meyer and Rowan, 1977), especially in situations when the PMS is imposed through 
external legislation (Yetano, 2013). Tilcsik (2010) analyzed decoupling as a process and not as an output, showing how the phenomenon unfolds over time. Basing his analysis on the case of a governmental agency, he claimed that decoupling is unsustainable as a long-term strategy. However, he stressed that, in order to comply with a new practice, the process requires the involvement of individuals who are both motivated and have power. Kelly et al. (2015) provided evidence from the healthcare sector in Ireland regarding how clinical staff perceived the decoupling of formal practices from those effectively in use within the Irish Health Authority. They found that a project which was supposed to promote an innovative reform to performance management processes was, instead, regarded as a “one size fits all” exercise.

This study investigates the reasons why different PMS implementation patterns emerge in similar contexts with the same externally imposed PMS and similar professional expertise. This issue was examined in several studies that analyzed the antecedents and determinants of a successful PMS implementation. Julnes and Holzer (2001) disentangled the adoption determinants from the implementation determinants, as the two types refer to different stages of utilization. The PMS implementation process - intended as actually using the performance measures - is strongly affected by cultural and political factors, especially those concerning external groups of interest. It was found that resources offer a significant prediction of implementation success, a result confirmed by Hoontis and Kim (2012). The latter authors argued that leadership support and the professionals' previous experience with performance measures are also important. Moreover, the readiness to compare performance across local governments is likely to be a factor related to the performance measures that will then be used. Indeed, benchmarking is commonly found to encourage the use of PMS throughout an organization (Ammons and Rivenbark, 2008; Hoontis and Kim, 2012; Gerrish, 2016). These studies all put emphasis on the determinants of a successful PMS implementation, rather than on the heterogeneity between different implementation patterns. In other words, we know 
which factors can favor PMS implementation, but not what can explain the diversity that is likely to emerge when comparing different cases. Taken together, the evidence presented in previous studies suggests that there is the need to learn more about why there are these different PMS implementation patterns within the context of NPM-style reforms where public institutions are required to adopt performance measures. For this reason, we have shifted attention from the "how" and "what" to the "why". More closely associated to this perspective, Mauro et al. (2018) analyzed the external and internal dynamics of defining performance-based budgeting at institutional level. They studied three Italian ministries through the lens of technical competencies, power, interests and value commitment (i.e. how committed are the actors involved to the newly introduced values), where all these factors are referred to as internal forces. Our analysis contributes to this specific strand of research with its application to the PMS sphere, whereby we have analyzed the heterogeneous patterns that emerge when implementing a PMS in different settings, here defined as the enabling step between PMS design and PMS use (Brignall and Modell, 2000). Moreover, given the importance that resources and expert support play in enabling such an implementation (Kroll, 2015), alongside analyzing the heterogeneity in PMS implementation processes, we have explored the role of professional experts, seen as an element which defines that process. This point is a distinctive element and is central to our research, since the role of professional experts during PMS implementation has been poorly addressed in the literature. Ter Bogt and van Helden (2011) studied an application in the Netherlands, showing that consultant-researchers can stimulate innovation within management accounting. Arnaboldi (2013) analyzed the role and evolution of the researcher-consultant applied to a performance measurement project conducted in a group of Italian universities. She identified three roles that apply to the consultant-researcher, technical translator, side-lined mediator and assembling explorer, finding that these roles emerged over time as the project reached higher levels of maturity. This study contributes to 
expanding the available literature on professional experts, placing emphasis on how they can influence the PMS implementation when they are brought into the process.

Given the picture here depicted, the contribution of this study is original within the strand of literature concerned with understanding the reasons behind the diverse PMS implementation patterns in contexts where resources - in the form of professional experts - are not a barrier but should, potentially, be enablers.

\section{Theoretical framework}

The theoretical framework adopted for our research is rooted in institutional theory, with specific reference to Old Institutional Economics (OIE) (Hodgson, 1988; Burns and Scapens, 2000). While the traditional branch of institutional theory (Meyer and Rowan, 1977; DiMaggio and Powell, 1983) places emphasis on external pressures, suggesting that institutions tend to imitate others successful in the same field, OIE instead concentrates on internal organizational dynamics. This specific focus is aligned to our purpose of investigating how the PMS implementation process differed so substantially between three municipalities where the starting point was the same for all three, rather than trying to determine whether stakeholders were legitimizing the PMS itself.

OIE focuses specifically on rules, routines and institutions (Hodgson, 1988). A rule is defined as a formal internal procedure; and a routine, or habit, is a form of self-sustaining, nonreflective behavior that arises in repetitive situations (Hodgson, 1988, p. 178). When made part of the ordinary activity, routines become behavior that is taken for granted, and this then transforms into new rules. Within this context, individuals play a central role in shaping and transforming the rules and routines: "OIE-inspired authors recognise that individuals operate in a specific social setting in which institutionalised rules and values, rather than some principle of rationality, often shape behaviour" (Ribeiro and Scapens, 2006, p. 98). These key OIE pillars suggest that we should look more closely at internal organizational dynamics and, in particular, 
at the role played by individuals in shaping the rules and routines that allow a PMS to be implemented within an organization (Burns and Scapens, 2000; Ribeiro and Scapens, 2006).

OIE has been widely applied to public administration research, including studies on PMS implementation. In this respect, some authors have investigated the interplay between formal rules and internal habits and how this exchange shapes the implementation of new PMSs (e.g. Burns and Scapens, 2000; Modell, 2004; ter Bogt, 2008; Pina et al., 2009). For example, Burns and Scapens (2000) pointed out that routines are established as old rules become redundant during the process of implementing a new accounting practice. In a similar vein, Modell (2004) stressed that performance measures in public institutions are often reshaped through the synergy between internal rules and routines.

The common trait of studies that endorse OIE as the means to investigate PMS implementation relates to the centrality of individuals and their actions and to organizational culture, both aspects crucial in shaping and affecting the implementation process. Building on this, and given the common external context, we focused our attention on internal organizational dynamics, defined as endogenous dynamics that drive organizational change (Greenwood and Hinings, 1996).

Following this literature and, in particular, the perspective suggested by Azzone and Palermo (2011), we have identified the three relevant aspects that should be analyzed in order to explore the PMS implementation process; they are power dynamics, communication and the inclination to learn. These aspects lie at the intersection between analyzing the dynamics driving the management of organizational change (Beer and Noria, 2000; Coram and Burnes, 2001) and analyzing accounting change in particular (Burns, 2000).

Power dynamics. This aspect refers to "the means through which intentions are to be achieved" (Burns, 2000, p. 569). Power, in this sense, does not relate specifically to the institutional role of the actors, but to their ability of promoting or resisting new accounting 
practices. As Greenwood and Hinings (1996) have stated: "Organizationally defined groups vary in their ability to influence organizational change because they have differential power. [...] Some [groups or individuals] have more potential or less potential for enabling or resisting change" (Greenwood and Hinings, 1996, p. 1038). Power dynamics are revealed through the PMS sponsors' level of involvement in promoting and nurturing the entire implementation process. Political engagement is also particularly relevant. Involvement at this level can also emerge when analyzing new rules introduced in connection with new formal initiatives linked to the PMS implementation. At the same time, the power of middle and lower levels also plays a significant role in explaining how some routines become institutionalized. On this point, the available literature on PMS implementation in public sector organizations has demonstrated that internal resistance put up by senior management and administrative staff can have a negative effect on the successful implementation of a performance system (e.g. Radnor and McGuire, 2004; Ribeiro and Scapens, 2006; Rantanen et al., 2007).

Communication. This is the second internal organizational dynamic and refers to the formal and informal mechanisms that are adopted to spread the new PMS throughout the organization. Studies have shown that communication is a positive asset for gaining internal consensus during the implementation of the PMS (Graetz, 2000; Jääskeläinen and Sillanpää, 2013). Communication is strictly associated to how rules and routines are spread throughout the organization, favoring the institutionalization of a new PMS. Formal practices and informal communication approaches must both be taken into consideration when investigating the dynamics of communication in order to trace the evolving dynamics of the rules and routines connected to the new system. In this respect, organizational complexity is likely to act as the facilitator or inhibitor of internal communication (Argenti et al., 2005).

Inclination to learn. This is, instead, related to whether individuals are able/willing to find out more about a new way of doing things (Kloot, 1997). This concept is broader than the 
mere gathering knowledge per se. As Deschamps and Mattijs (2018) stated, "Knowledge is accumulated by individuals, but it must be transferred to the rest of the organisation or institutionalised in some way before we can consider that learning has happened" (Deschamps and Mattijs, 2018, p. 474). Associated to this aspect is the need to investigate what competencies people currently have and whether they can acquire new skills during the implementation of a new accounting practice.

In summary, these three aspects informed our investigation into the "why" of the different PMS implementation patterns within the three Italian municipalities.

\section{Methods}

\subsection{Research Methodology}

The research methodology adopted is that of a participatory case study, defined as "a mode of case study research that involves the participants, local groups, or the community in all phases of the research process" (Reilly, 2010, p. 658). The case study involved three Italian municipalities engaged in implementing a PMS with the support of professional experts. The PMS implementation project was part of a governmental program where the final aim was to create a benchmarking network among Italian municipalities. The project was promoted by the Agenzia per la Coesione Territoriale, a central government agency to support projects and programs for economic development. Given the heterogeneity observed in the project implementation under study, we have unfolded the academic issue of why different PMS implementation patterns emerge in similar contexts, involving the same externally imposed PMS and where the implementation was carried out with the help of professional experts. In this project, the three authors were the professionals experts - and they were also the primary technical referents for the PMS implementation. They were assisted by two junior researchers, all highly qualified in the field of performance measurement and management. 
The project started with a pilot case on three municipalities, selected jointly by the research group and the ministerial agency. The municipalities did not face any additional expense as the entire project was financed by the Agenzia per la Coesione Territoriale and they only had to cover the cost of staff time for personnel working on the project. It is important to underline that the municipalities were invited to take part in the project and were free to accept or not. The intention was not to form a sample that was representative of all Italian municipalities, but of showcasing different contexts where PMSs were implemented, where the different municipality staff numbers and local population sizes acted as a proxy for organizational complexity. At the same time, to avoid introducing any external context features that could affect the PMS implementation, all the municipalities chosen are located in the same northern Italian macro area. Table 1 gives a brief description of each.

[Table 1] around here

The PMS implementation process started from homogeneous initial settings, in that (i) none of the municipalities had already implemented a PMS which could have been used for the project; (ii) in all of them, technical knowledge about performance measurement was limited and in the hands of technical staff; (iii) all had similar organizational structures, with mayors and/or general secretaries involved formally in the launch of the project and the data collection phase - as described later in the paper; and (iv) the three general secretaries came from similar backgrounds, as all three had held similar positions in other municipalities.

Our empirical material came from three main sources, namely, meetings with the key actors involved in the PMS implementation process, participant observations and secondary sources. The first and most important data sources consisted of the plenary meetings attended by the authors, all three municipalities and the Agenzia per la Coesione Territoriale, the plenary meetings with the single municipalities and the ad hoc meetings with municipality staff representatives (see Table 2). 
[Table 2] around here

The function of the first plenary meeting held at each municipality was to gain the political consensus of the mayors and/or general secretaries (phase 1), while the planning and organization of the PMS implementation process itself was determined during the subsequent plenary meetings (phase 2). More precisely, this related to the (potential) adjustment of metrics for indicators, the methodology and responsibility for collecting data and the timing for each activity. There were three such meetings, one for each municipality, attended by the research group and, for each municipality, the main sponsor of the project and the operational project leader. Twelve ad hoc meetings were held with administrative staff responsible for each PMS area throughout the duration of the project (phase 3). These meetings were followed up by emails, skype calls and phone calls, to support staff during the process of collecting data necessary for implementing the PMS. Lastly, the benchmarking results were discussed at a plenary meeting in the presence of the main sponsors and the Agenzia per la Coesione Territoriale (phase 4).

During each meeting, the authors were able to gain further empirical material through informal interviews with each of the actors involved, namely the mayor, general secretary, the head and staff in Administration and Finance ot the heads of Purchasing, School Services and School Maintenance (the areas most involved in the PMS implementation).

Participant observations at each of the above meetings provided the second source of data. These observations were extremely useful in terms of grasping the micro organizational dynamics of power, communication and inclination to learn between the actors involved in the project. We observed each person's individual commitment to organizing and participating in the project, the way people in the same municipalities interacted with each other, the types of contribution each of them provided to the discussions and the way they connected with the professional experts. Secondary sources were then used to complement the case study material. 
Performance-related documentation for each municipality was collected before the first meeting (i.e. strategic plans, performance plans and internal reports on strategic priorities and actions).

A summary of the key insights was prepared at the end of each meeting, with the double purpose of, firstly, drawing up an outline of the technical aspects of the PMS to be implemented and, secondly, providing a synthesis of the organizational dynamics concerning the implementation of the PMS. More specifically, each author prepared a summary table comparing the three municipalities over the time in which the PMS was developed, and these were the bases for comparing the three aspects investigated (communication, power and inclination to learn). Empirical evidence was derived from statements recorded during meetings and from participant observations. The comparative analyses prepared by the three authors were used as the starting point for the theoretical elaboration of the empirical material, and these insights were compared with the available literature. Therefore, the data analysis was an iterative process shifting between theory and empirical data on communication, power and inclination to learn. This meant that it was possible to prepare a narrative for each municipality in line with the key dimensions of the theoretical framework, completing the picture with a critical analysis of the external experts' influence over each of the three dynamics. These narratives have been re-elaborated here and presented according to the key dimensions of the framework.

\subsection{Research setting}

The research setting is the local government within Italian municipalities. Local governments in Italy have recently been put under pressure on three fronts to implement PMSs, placing emphasis on the need for them to be more efficient in their operations and in how they use their resources to produce and deliver local public services. 
The first pressure relates to the law requiring every local government to develop a Performance Plan (Brunetta Decree, no. 150/2009). Inspired by the New Public Management philosophy (Hood, 1991), this reform directed each local government to define their expected objectives (strategic and operational) with quantifiable targets. In so doing, they also had to align their financial programs to the expected targets and, when pursuing their objectives, they had to demonstrate a high level of economic efficiency. These Performance Plans must specifically indicate how resources are allocated as efficiently as possible to ensure that the results are achieved. The procedures for developing and implementing the Performance Plans were updated through reforms set out in Decree 74/2017, but the key elements of stimulating and measuring efficiency have been maintained and strengthened.

The second pressure urging local governments to give serious attention to performance measurement came with Law 42/2009, which introduced a reform to how national government allocates resources to local governments. The funding mechanism had traditionally been based on the expenditure levels of previous years (known as 'historical costs'), and it perversely encouraged wasteful spending. Law 42/2009 was introduced to correct this vicious circle, stating that grants must be allocated on the basis of standard financial needs, and these had to be estimated through an econometric model. The model considers efficient spending in each local government on a case by case situation, examining aspects that relate to the local context and the volume of public services delivered. SOSE (Solutions for the Italian Economic System), an agency set up by the Ministry of Treasury and the Bank of Italy, is responsible for collecting administrative and survey data from local governments. As part of its remit, SOSE is also expected to run simulations and estimations on the efficiency of local government spending. Trials on the new allocation system were initially carried out in 2015 and the system is now being used progressively, year after year, to distribute national funds allocated to local government (around 50\% of the total in 2018). As a consequence of this new system, all 
municipalities are expected to keep a close eye on how they use their resources most efficiently, and this, in turn, is a parameter used when determining the national resources that will be allocated to each, with performance measures becoming more and more wide-spread accordingly.

The third pressure behind adopting PMSs is the continuous reduction in overall funding available for local governments, a common issue in a number of OECD countries. An analytical description of the funding sources available to Italian local governments and the subsequent accessible spending is well beyond the scope of this paper; what is important here is to indicate that spending levels have been severely curtailed over a relatively short timeframe. Total expenditure in local governments (including the local governments at regional and provincial level - "Regions" and "Provinces") was 240 billion euros in 2016, the same level as in 2011 (in nominal terms). For these two years, the expenditure in the various central government ministries and departments was 495 billion euros (in 2016) and 452 billion euros (in 2011), an increase of $9.5 \%$ (source: Ministry of Treasury). It is also important to bear in mind that all spending reviews conducted by the Italian government (Arena and Arnaboldi, 2013) led to cuts being made and government budgets being reduced.

The three normative pressures described above suggest that municipalities were virtually obliged to develop internal PMSs, as these can support decision-making processes where the aim is to maximize performance while keeping resource usage constant, or even reducing overall spending levels. Although the methodological and conceptual challenges - and limitations - when measuring performance in the public sector are, in general, well-known (van Thiel and Leeuw, 2002; Heinrich, 2012), there are always strong reasons - in this case the continuous pursuit of higher levels of efficiency - for building comprehensive performance systems in local governments. The value of the project for the three municipalities lies in the 
potential building of a performance culture based on a network of municipalities facing similar challenges.

\section{Results}

The results show that different implementation patterns emerged within the three municipalities, with differences also being found in the roles played by the professional experts and the internal organizational dynamics during the implementation process. It is important to underline the fact that the external pressures were similar in all three cases, in terms of (i) PMS design (since the set of measures and indicators were proposed by the professional experts and improved on through interaction with the municipality managers) and (ii) external normative pressures.

Notwithstanding the similar external pressures and design, different PMS implementation processes emerged in the three municipalities. The three implementation patterns have been labelled formal compliance, shared vision and technical oligarchy.

The paper does not present the results longitudinally following the development of the project, but concentrates on the three main aspects that differentiate the PMS implementation paths of the three municipalities - power dynamics, communication and the staff's inclination to learn (Table 3). In this respect, we have assumed that the theoretical dimensions are able to proxy additional elements likely to play a major role in influencing the process of implementation. Among these are political commitment (captured by the power dynamics), technical competence - both existing and newly learnt - within management (discussed together with inclination to learn) and organizational complexity (which could influence internal communication). It is also important to remember that the focus here is not on the design of the PMS, which is mainly the starting point for the investigation, but on the process followed to implement the system. Organizational dynamics came into play during the PMS implementation phases regardless of the goodness of fit of the indicators, bearing in mind that 
these were all agreed with the municipalities taking part in the study to ensure that we avoided any internal resistance arising from measures imposed from the outside.

[Table 3] around here

\subsection{Power Dynamics}

The term power dynamics refers to the attitude held by senior, middle and lower ranking staff towards promoting or resisting change within the organization. In terms of senior management commitment, in all the three municipalities, the project was sponsored by both the highest political official (the mayor) and the senior administrative executive (the general secretary). They all approved the pilot project, but their level of involvement differed from one municipality to another, as did the commitment and engagement of other people within the organization.

Municipality A, where the outcome was labelled as formal compliance implementation. The senior administrative executive showed an initial high commitment, stating, during an initial meeting:

This is big opportunity for us. We don't have a stable set of indicators to measure efficiency and effectiveness in how we deliver our public services. Some areas have their own set of data but, at the top administrative level, we have no uniform and comparable set of data. This is a wonderful opportunity for us to improve how we manage our public services (General Secretary - Municipality A).

This initial enthusiasm decreased over time, with the general secretary not responding to any kind of internal communication or follow-up about the progress of the PMS implementation. The head of IT was formally appointed by the general secretary to take over the operational management of the project. In his case also, his commitment was high in the early phase of the project, and he gave his support to an internal plenary meeting involving the person/s responsible for the public services being analyzed (school maintenance, school 
canteens and purchasing), together with the entire control office staff. This meeting was an excellent occasion to share the purposes, scope and details of the project internally and discuss the relevant indicators and metrics. Several metrics were adjusted during the meeting and suitable sources of data were identified. However, after this initial enthusiasm, the operational project leader's commitment dropped. He gave no help in organizing meetings, collecting data or feeding data to the PMS. Because of the lack of commitment on the part of both the general secretary and the operational project leader, the external professional experts had to press for data, and they contacted the administrative offices directly. While neither the general secretary nor the operational project leader explicitly exercised their power to resist the implementation, they were effectively "out of view", demonstrating how the lack of "supporting" power leads to a struggling implementation process. As a result, the professional experts pressed continuously for information until almost all the data needed to compute the previously agreed KPIs were collected. The professional experts exerted greater pressure as the power dynamics decreased. The implementation process was complex, in part because of the limited engagement on the part of staff at the lower levels, as shown by this phone call with the referent from the school construction service:

Sorry for the delay in sending the data, but we are being constantly overwhelmed by requests and deadlines and I had to set priorities. I also waited for ages for my colleague to confirm the data, but he only came back to me today. As the general secretary had not appointed him as an official referent in the project, he felt he could take more time to collect the data (Person responsible for School Construction Services - Municipality A).

No further meetings to share the results internally were arranged, either with the administration office or with senior administration executives.

Municipality B, where the outcome was labelled as shared vision implementation. Here the situation was the opposite, with power distributed throughout the municipality. Initially, the 
mayor and general secretary were very committed. The general secretary formally appointed the head of the control office as the operational leader of the project, but he also remained strongly involved in all the implementation phases, attending almost all the internal plenary meetings and wanting to be copied in to a number of the emails. He never pushed the project directly, but gave the professional experts an official internal role, which allowed them to collect data and conduct interviews. A particular feature of this municipality was that power was distributed among the various administration people involved in collecting data. This was especially the case for the heads of the control office, of the school canteen services, of purchasing and of school maintenance. All of them were highly engaged in the project, attending all the meetings along with their internal staff and they were all keen to share information, problems and doubts. People at the lower levels sometimes did not have the technical expertise to collect data, so they asked the experts for accurate technical information. While the data collection process ran more smoothly, some employees saw the project as a chance to "stand out" and "shine" above their colleagues. In this way, the actors were exercising their power in close relationships, bringing it into the sphere of personal interests. This issue emerged from the following exchange during a meeting about FTE data collection in school canteens:

Head of the Control Office: I can give you the data using our internal annual analysis.

Head of Social Services: No, you can't. I'm responsible for these services and I'm the best person to explain how time is allocated to different activities.

Head of the Control Office: Of course, you know what you do, but I have data for all the services. If we use my data, we know we can compare it with the other services.

Head of Social Services: That data will be misleading. I want to check each and every thing and make corrections. 
This one example indicates the intense (occasionally heated) involvement of everyone working in the project.

Municipality $\mathrm{C}$, where the outcome was labelled technical oligarchy implementation. This case differs from the previous two situations, in that it reveals high levels of power and commitment, but only among the technical staff in the control office. Senior officials were only involved to the extent of sending emails to approve the work carried out by the external professional experts. Neither the mayor nor the general secretary attended the internal meetings or joined in project-related communications. The entire project was led by the three-person control office staff. Internal meetings, when organized, were only attended by these three people. When the professional experts wanted to arrange meetings with the heads of the services involved in order to validate the KPIs and gain further clarifications about the service delivery and internal organization, the technical staff's response was:

But meetings with other internal offices are useless. You'd find it hard to talk to them as they don't like indicators. We have everything you need. Look at our database, it holds all the data we collect on the other offices. We can give you all the data to feed to the PMS. (Head of the Control Office - Municipality C)

Any following decision or responsibility was in the hands of the control office, and they collected data independently from all the other offices involved in the project. Their personal commitment was not based on any formal pressure but, apparently, because of their genuine interest in adopting a new accounting system. In this respect, the dynamics of power that came into play during the implementation process were facilitated by the high level of technical knowledge among the actors involved. 


\subsection{Internal Communication}

Communication plays an important role in the process of institutionalizing the rules and routines for the PMS implementation. Looking at these internal organizational dynamics, here also we found different patterns between the three municipalities.

In the formal compliance implementation of Municipality A, there was no internal communication and this part was, in fact, passed on to the professional experts. They were responsible for spurring on the internal staff at all levels, asking for feedback about the indicators and for data to elaborate the required measures. The head of IT, who was appointed as operational project leader, was not actively engaged after the initial meeting. This resulted in poor internal communication, as nobody in a senior or facilitating position was overseeing this aspect. As a natural consequence of this, nobody communicated with the rest of the organization to inform them about the new tool.

In the shared vision implementation of Municipality B, on the contrary, communication among offices was highly visible and took place both formally and informally. Unlike in the previous case, communication here was pushed internally by staff. The lower levels in the organization, in particular, supported and shared communications, especially on an informal basis. As reported by the school services referent during a follow-up call:

My colleague from the school construction office told me that they have sent you the data. I had a small doubt about the period covered in one of the KPIs, so I checked with her whether I had understood the indicator correctly. Now I'm sure that all the data we're providing is for the same period, as I think it's extremely important (Head of School Canteen Services - Municipality B).

This high level of communication between the offices accelerated the process of collecting data and, in addition, the research group was also working simultaneously with all the various departments on this aspect. All the people in administration were keen to interact 
with the research group, sharing their doubts, talking about other options or simply making considerations about the data, showing concern not only for their work but also for that of their colleagues.

Lastly, the technical oligarchy implementation of Municipality $\mathrm{C}$ resulted in formal communications being pushed by the internal technical staff. Because the technical staff centralized the operations and took control during the PMS implementation, they established a formal line of communication directly between their unit and the people responsible for providing the data to feed into the PMS. The other offices within the municipality were unaware of the final aim of the project and took no active part in collecting data or in the PMS revision phase. The main justification was the following:

We look after the control office. We have recently implemented this new tool [name omitted] to collect data about the efficiency and effectiveness of individual operations. Every head of department on the administration side the municipality must now input data to this system, in part because it's connected to bonuses and incentives. We can extract data from this system to use in reports and give you the data you need (Head of the Control Office Municipality C).

Regarding the role played by the external experts, internal staff were proactive in communicating if and when they felt their knowledge on specific topics to be inadequate, but communication was very limited otherwise.

\subsection{Inclination to learn}

The term inclination to learn refers to how willing individual employees were to learn from the PMS implementation process. The willingness of individual people to change their attitudes, habits and routines is fundamental in consolidating a new accounting practice (Burns and Scapens, 2000). This is relevant for all levels within an organization. 
In the formal compliance implementation of Municipality A, the staff's inclination to learn was very low, as the managers did not have the expertise to develop or implement the PMS and, on top of that, they were not interested in learning or making this knowledge part of the organizational routines. This interpretation was supported by the lack of intentional changes to any of the processes or routines, an attitude observed during the overall implementation process.

In the shared vision implementation of Municipality B, the staff's inclination to learn was particularly high among the lower ranking levels, as these people did not have the necessary technical expertise. The staff collaborated actively to fully exploit the potential gains from the PMS, with every person from administration engaging with the expert group, asking questions and wanting explanations and more material. Their interest in the PMS and the new system was high, and this activated the gradual process of guiding an organization towards learning. This approach fostered continuing positive interaction with the professional experts throughout the project.

Finally, in the technical oligarchy implementation of Municipality C, staff inclination to learn was erratic throughout the process. As already mentioned, the technical middle level staff acted as reference group, and they centralized the project. These people, because they belonged to the control area, owned at least some of the technical skills needed in performance management and measurement. Their inclination to learn was, however, highly variable. In some cases, they seemed keen to find out more, asking for support and further clarifications. For example, they were unaware of the activity-based management methodology for computing FTEs and were particularly keen to learn more about it. In other cases, they showed absolutely no desire to learn. We saw this first-hand when we were introducing a survey to measure the perceived effectiveness of school canteen and school maintenance services. The technical staff were not interested in this aspect as it was not part of the administration's strategic plan, and 
they had no wish to understand this issue any further. We found that an inclination to learn and an inclination towards change emerged only if the new practice was somehow related to the current organizational status - i.e. as a sort of selective learning process. Indeed, whenever the referents saw that they were able to manage a specific part of the data collection process on their own, they went about it without checking with the professional experts.

\section{Discussion}

Empirical evidence has shown that there are different patterns for PMS implementation in the municipalities being investigated, here called formal compliance, shared vision and technical oligarchy implementations. These different patterns are interpreted through the lens of internal organizational dynamics, in combination with the study's element of originality, that of professional experts prompting the PMS implementation process.

The formal compliance implementation pattern, exemplified by Municipality A, is defined by power concentrated in the hands of senior administration, but this was only when the PMS was initially activated. The senior levels became progressively less committed and engaged in the project over time, while the middle and lower levels were never entirely engaged. Communication, in turn, was mainly formal and significant only with regards to interaction with the professional experts - hence, it played no part as an internal driver for implementation. In this respect, we acknowledge the potential role played by organizational complexity, which acted as a barrier to communication, given that Municipality A was the largest of the three municipalities. Inclination to learn was almost absent at all the organizational levels, as demonstrated by the extremely poor level of interest in any of the methodological aspects relating to the implementation and possible replication of the PMS. This lack of interest was exacerbated by the managers' poor technical skills. The consequence of this situation was that the implementation was mainly driven by the external professional experts, and they had to push to make sure that the pilot project was completed. In this sense, 
the municipality's participation was highly formal but not substantial, prompting us to give this label to Municipality A.

The shared vision implementation pattern was the arrangement seen in Municipality B. It differed significantly from the previous pattern, since the power to lead the project was distributed throughout the organization. The senior, middle and lower roles were all involved, and a significant level of formal and informal communication ensured the proper evolution of the PMS. Most people involved, especially at the middle level, were keen to understand the system better and they were proactive in collecting data to compute the KPIs. Hence, the inclination to learn was quite high, although the level of internal expertise was not. However, individualism and power dynamics among the actors prevailed, with the result that many who supported progress in the project did so with the end purpose of increasing their own position in the organization. Despite this, a shared approach to the implementation process, especially from the lower management levels, was the most distinctive aspect that emerged during the project, and this elicited the label we gave this municipality.

Lastly, the implementation pattern of technical oligarchy was reflected in Municipality C. Differently from the two previous cases, the PMS implementation process was centralized in the hands of the control office and the three people there, all of whom were highly committed and engaged in the project. Their high engagement ensured a fast PMS implementation and their inclination to learn fluctuated throughout the project, depending on the specific PMS aspect. For example, when revising customer satisfaction questions to measure effectiveness in the school canteen service, their inclination to learn was low, while they showed a high level of interest when applying the activity-based-management methodology. This implementation pattern resulted in an "ambiguous" PMS implementation. The process was completely in the hands of a small group of technical experts within the municipality, and this was the reason for the label we assigned to the municipality. The PMS as initially conceived never led to entirely 
new routines. However, some indicators and methodologies connected to the externally imposed PMS were accepted internally and became part of a new management system. More specifically, the efficiency indicators obtained through an FTE calculator were regularly included in the evaluation of individual managers to quantify the time each spent on their assigned annual objectives.

This variety in PMS implementation patterns shows that, even when the external context and resources are the same, the PMS implementation is significantly affected according to whether the internal organizational dynamics (power, communication and inclination to learn) are aligned or not. Given the struggle to implement the PMS within the three municipalities, our claim is that one possible explanation for this is that, if one of the internal organizational dynamics is not sufficiently developed or is poorly linked to the others, the PMS implementation process is not complete. In this sense, the three theoretical dimensions in the implementation process act as the lens that can help us interpret the whys behind the heterogeneity we observed. From the power perspective, the results show that the innovative path towards using a PMS must be supported by the higher hierarchical levels, as this gives strength and legitimacy to the collection and use of data. Formal commitment is not enough, it must be joined by the empowerment of middle managers: political dynamics are fundamental throughout the process to promote the new tool and spread a positive outlook geared towards accepting the new accountability practice (Kroll, 2015). Communication becomes, at that point, a concrete lever that can enable the organizational shift. A clear understanding of the strategic goals and practical purposes is the necessary condition for cultivating a positive predisposition towards performance measurement procedures within an organization. This is valid both vertically (along the hierarchy, related to power dynamics) and horizontally (across offices), and is necessary to avoid the situation of technical oligarchy. In parallel, the entire organization is engaged in learning, in line with the ability of each person to gain knowledge from the 
implementation process. As the cases highlighted, when the three pillars are disjointed, this results in the PMS being adopted in a fragmented manner and not extending to the entire organization. Moreover, we found that this internal misalignment played a role in influencing how staff interacted with professional experts, who were the additional value supporting the implementation process. A top-down approach to communication and power and a low inclination to learn resulted in a somewhat strained working relationship with the professional experts, who had to play a "pushing" role throughout the implementation process. It is also true that a bottom-up approach, both in terms of power and communication and a distributed inclination to learn, led to a smoother interaction with the experts, but the outcome was that the PMS was not actually used. This was mainly because the power dynamics were closely related to personal interests and prestige rather than to organizational benefits. Finally, wherever power, communication and inclination to learn were restricted to technical people, the level of engagement with professional experts fluctuated, depending on whether the actors in charge saw any organizational benefits. Having said this, whenever the internal technical experts acknowledged the value of some part of the PMS, that part was then (partially) adopted.

\section{Concluding Remarks}

This research explores "why" Performance Measurement Systems (PMSs) follow different implementation patterns even when starting with the same initial external pressures. The question was addressed by investigating the empirical case of three Italian municipalities, where external professional experts had been supporting the PMS implementation process. The empirical case exemplifies a situation determined by a piece of legislation and where external professional experts were brought into the process, then resulting in a heterogeneous series of PMS implementation patterns. We based ourselves on the conceptual pillars of Old Institutional Economics (Burns and Scapens, 2000; Ribeiro and Scapens, 2006), with its focus on internal organizational dynamics, and used power dynamics, communication and an inclination to learn 
as the conceptual lenses for interpreting these heterogeneous PMS implementations. The results bring up three very different PMS implementation patterns (formal compliance, shared vision and technical oligarchy), which vary in terms of power dynamics, communication and inclination to learn. These internal organizational dynamics, in turn, affected the interaction between the organizational roles within the municipalities and the external professional experts. In one case (formal compliance), the PMS implementation process was driven by professional experts, internal commitment was limited, and it was a struggle to complete the implementation process. The other two cases reflect rather unusual cases. The shared vision implementation process largely involved staff at the municipality keen to communicate and to learn. However, the actors' individualism prevailed, and middle ranking staff took advantage of the project to improve their own skills and gain internal visibility. This turned into a lack of a unitary approach for the implementation of the PMS, despite the initial shared vision. The technical oligarchy approach, instead, consisted of a centralization of power, communication and inclination to learn in the hands of a specialized middle level internal group. While this ensured a fast PMS implementation, it did not allow the new system's rules and routines to be spread.

The results presented in this study are relevant for the debate on PMS implementation in complex public organizations (e.g. van Thiel and Leeuw, 2002; van Helden et al., 2008; Yetano, 2013; Taylor, 2014). Three main insights can be derived from this work.

First, given a certain institutional setting defined by external factors - in this case, national laws and incentives for efficiency - internal dynamics are shown to play a crucial part in the implementation of a PMS (Burns and Scapens, 2000; Ribeiro and Scapens, 2006; Yetano, 2013). The situation in Italy reflects this specific case, because the recent reforms were clearly devised to compel local governments to search for greater efficiency - through direct and indirect incentives that range from reputation to various grants from national government. In this context, we found that the differences in implementing a PMS did not depend on a mix of 
external forces in play, but to different internal cultures and the organizations' capacity to react to them. Our findings certainly point in this direction. The three levers observed and used to classify the cases (power dynamics, communication and learning) all refer to differences in the way the organizations work and to their management attitudes and operational practices.

Second, it was shown that providing external resources to improve internal acceptance of performance measurement is not enough to ensure that the PMS would be truly applied. In the public sector literature, the lack of adequate financial and human resources has often been referred to as a key issue that prevents innovation from being introduced to organizational management (Julnes and Holzer, 2001; Ohemeng, 2010). This is not the case here, since the necessary resources were provided by the Italian government, and the professional experts conveyed the necessary technical expertise. In all three cases, one or more internal organizational elements undermined the positive effect of the professional experts - as did the lack of political commitment (power dynamics), the scarce communication between key actors and the missed chances to change organizational practices and attitudes (learning). These findings call for renewed attention to the relative influence exerted by external and internal variables, with the latter being related to the long-term effects of organizational culture on the organization's ability to monitor performance effectively. Moreover, the results show that the presence of professional experts cannot be a sufficient condition throughout the implementation process. Thus, simply providing technical knowledge cannot by itself trigger a positive implementation process until the internal organizational elements become aligned.

Third, the choice of people and actors to be involved during the implementation of the PMS is not neutral with respect to the observed patterns (Taylor, 2014). This study reveals specifically that three main organizational roles are crucial within the implementation of a PMS. These are the sponsor/s (that is, the people representing the highest level decision-makers in the organization, necessary to secure the right commitment), the technicians (who are able to learn 
from the experts and create the technical prerequisites for the PMS to work) and the organization's facilitators (who can spread the innovation across people and units). These roles relate to each of the theoretical dimensions referred to previously, and this highlights the importance of involving people who can encourage power dynamics, learning and communication in order to fully implement a new accounting routine. If one or more of these figures are not actively involved in the project, this in turn can easily become a formal procedure or a technical exercise and is unable to affect the organization's long-term plans.

At policy level, we offer some considerations about the competence/expertise of senior and middle ranking managers who are expected to be in charge of designing and feeding the PMS. When designing laws that affect accounting systems, policymakers should ensure that human resources within the interested organizations have the skills necessary to implement the system. This is not only for reasons of compliance, but because they must provide a system that fully supports the organization, and this cannot happen if managers do not have the full set of competences needed. Hence, when policymakers require an accounting system to be designed, alongside this, they should also provide an appropriate training program.

In the light of the results presented in this work, two topics deserve further attention. The first is the role played by strategic planning and budgeting in shaping the adoption of a PMS. In our project, the PMS was implemented after selecting the cases ex ante and no further analyses were conducted to assess whether the selected organizations were actually able to conduct a robust strategic planning process. Whatever the case, future studies should explicitly target the interplay between these two important phases of strategic control (planning and measurement/evaluation). Secondly, there are examples of local governments (in Italy and elsewhere) which have been successful in their implementation of a PMS. A comparison between these realities and the cases presented here could shed more light onto the differences in terms of the commitment and practices that led to different results. 
This study has a limitation in that the investigation was restricted to three Italian municipalities and cannot, therefore, be representative of all local governments. By grounding our research on solid theoretical bases, we have ensured the internal validity of our findings, while we acknowledge its limitations in terms of external validity. Moreover, it can be the case that the way in which the PMS was designed (i.e. the goodness of the indicators) can influence the quality of the implementation process. To overcome this limitation, we agreed all the KPI definitions together with the municipality operational project leaders in order to ensure that the PMSs could be adapted and compared, given that the aim of the project was to set up a performance benchmarking process. Finally, the study ran over a fifteen month period, and we were no longer involved directly in the organizations after the PMSs were implemented, meaning that we do not know how intensely or otherwise internal evaluation cultures changed as a result of the project. This is also an avenue for future research, and it would be extremely interesting to explore whether, when a PMS is implemented in one way or another, this is associated to the system being used differently, and could certainly provide additional insights for the managers in local governments.

\section{References}

Agostino, D., and Arnaboldi, M. (2017). Rational and ritualistic use of key performance indicators in hybrid organizations. Public Money \& Management, 37(6), 409-416.

Akbar, R., Pilcher, R.A., and Perrin, B. (2015). Implementing performance measurement systems: Indonesian local government under pressure. Qualitative Research in Accounting \& Management, Vol. 12 Issue: 1, pp. 3-33

Ammons, D.N. (2013). Signs of Performance Measurement Progress Among Prominent City Governments. Public Performance and Management Review, 36:4, pp. 507-528

Ammons, D. N., and Rivenbark, W. C. (2008). Factors influencing the use of performance data to improve municipal services: Evidence from the North Carolina benchmarking project. Public Administration Review, 68(2), 304-318.

Arena, M., and Arnaboldi, M. (2013). Debate: Dealing with spending reviews-Italy. Public Money \& Management, 33(1), 4-6.

Argenti, P. A., Howell, R. A., and Beck, K. A. (2005). The strategic communication imperative. MIT Sloan management review, 46(3), 83-89. 
Arnaboldi, M. (2013). Consultant-researchers in public sector transformation: an evolving role. Financial Accountability \& Management, 29(2), 140-160.

Azzone, G., and Palermo, T. (2011). Adopting performance appraisal and reward systems: A qualitative analysis of public sector organisational change. Journal of organizational change management, 24(1), 90-111.

Barbato, G., and Turri, M. (2017). Understanding public performance measurement through theoretical pluralism. International Journal of Public Sector Management, Vol. 30 Issue: 1, 1530

Beer, M., and Noria, N. (2000). Cracking the code of change, Harvard Business Review, MayJune, pp. 133-141.

Behn, R. D. (2003). Why measure performance? Different purposes require different measures. Public administration review, 63(5), 586-606.

Brignall, S., and Modell, S. (2000). An institutional perspective on performance measurement and management in the 'new public sector'. Management accounting research, 11(3), 281-306.

Burns, J. (2000). The dynamics of accounting change inter-play between new practices, routines, institutions, power and politics. Accounting, auditing \& accountability journal, 13(5), 566-596.

Burns, J., and Scapens, R. W. (2000). Conceptualizing management accounting change: an institutional framework. Management accounting research, 11(1), 3-25.

Camilleri, E., and Van Der Heijden, B. (2007). Organizational commitment, public service motivation, and performance within the public sector. Public Performance \& Management Review, 31, 241-274

Coram, R., and Burnes, B. (2001). Managing organizational change in the public sector. The International Journal of Public Sector Management, Vol. 14 No. 2, 94-110.

De Bruijn, H. (2003). Managing performance in the public sector. Routledge.

Deschamps, C., and Mattijs, J. (2018). How Organizational Learning Is Supported by Performance Management Systems: Evidence from a Longitudinal Case Study. Public Performance \& Management Review, 41(3), 469-496.

DiMaggio, P., and Powell, W. W. (1983). The iron cage revisited: Collective rationality and institutional isomorphism in organizational fields. American sociological review, 48(2), 147160.

Fryer, K. Antony, J., and Ogden, S. (2009). Performance management in the public sector. International Journal of Public Sector Management, 22(6), 478-498.

Gerrish, E. (2016). The impact of performance management on performance in public organizations: A meta-analysis. Public Administration Review, 76(1), 48-66.

Goddard, A., Assad, M., Issa, S., Malagila, J., and Mkasiwa, T. (2016). The two publics and institutional theory - A study of public sector accounting in Tanzania. Critical Perspective on Accounting, 40, pp. 8-25 
Graetz, F. (2000). Strategic change leadership. Management decision, 38(8), 550-564.

Greenwood, R., and Hinings, C. R. (1996). Understanding radical organizational change: Bringing together the old and the new institutionalism. Academy of management review, 21(4), 1022-1054.

Johansson, T., and Siverbo, S. (2009). Explaining the utilization of relative performance evaluation in local government: a multi-theoretical study using data from Sweden. Financial Accountability \& Management, 25(2), 197-224.

Julnes, P. L., and Holzer, M. (2001). Promoting the Utilization of Performance Measures in Public Organizations: An Empirical Study of Factors Affecting Adoption and Implementation. Public Administration Review, 61(6), pp. 693-708

Heinrich, C. J. (2012). Measuring public sector performance and effectiveness. The SAGE handbook of public administration, 32 .

Hodgson, G.M. (1988). The Approach of Institutional Economics. Journal of Economic Literature, 36(1), pp. 166-192.

Hood C. (1991). A public management for all seasons?. Public Administration, 69 (1): 3-19.

Hoontis, P., and Kim, T. (2012). Antecedents to municipal performance measurement implementation: A case study of two New Jersey Municipalities. Public Performance \& Management Review, 36(1), 158-173.

Jääskeläinen, A., and Sillanpää, V. (2013). Overcoming challenges in the implementation of performance measurement: Case studies in public welfare services. International Journal of Public Sector Management, 26(6), 440-454.

Keerasuntonpong, P., and Cordery, C. (2018). How might normative and mimetic pressures improve local government service performance reporting?. Accounting \& Finance, 58(4), 11691200.

Kelly, R., Doyle, G., and O'Donohoe, S. (2015). Framing Performance Management of AcuteCare Hospitals by Interlacing NPM and Institutional Perspectives: A New Theoretical Framework. Financial Accountability \& Management, 31(1), 69-91.

Kloot, L. (1997). Organizational learning and management control systems: responding to environmental change. Management Accounting Research, 8(1), pp. 47-73.

Kloot, L., and Martin, J. (2000). Strategic performance management: A balanced approach to performance management issues in local government. Management Accounting Research, 11(2), 231-251.

Kroll, A. (2015). Drivers of performance information use: Systematic literature review and directions for future research. Public Performance \& Management Review, 38(3), 459-486.

Mauro, S. G., Cinquini, L., and Grossi, G. (2018). External pressures and internal dynamics in the institutionalization of performance-based budgeting: an endless process?. Public Performance \& Management Review, 41(2), 224-252.

Meyer, J. W., and Rowan, B. (1977). Institutionalized organizations: Formal structure as myth and ceremony. American journal of sociology, 83(2), 340-363. 
Modell, S. (2004). Performance measurement myths in the public sector: a research note. Financial Accountability \& Management, 20(1), 39-55.

Ohemeng, F. (2010) The dangers of internationalization and one-size-fits-all in public sector management: Lessons from performance management policies in Ontario and Ghana, International Journal of Public Sector Management, Vol. 23 Issue: 5, pp. 456-478

Pina, V., Torres, L., and Yetano, A. (2009). Accrual Accounting in EU Local Governments: One Method, Several Approaches. European Accounting Review, 18(4), pp. 765-807.

Poister, T. H., and Streib, G. (1999). Performance measurement in municipal government: Assessing the state of the practice. Public Administration Review, 325-335.

Pollitt, C. (2001). Clarifying convergence. Striking similarities and durable differences in public management reform. Public Management Review, 3(4), 471-492.

Propper, C., and Wilson, D. (2003). The use and usefulness of performance measures in the public sector. Oxford review of economic policy, 19(2), 250-267.

Radnor, Z., and McGuire, M. (2004). Performance management in the public sector: fact or fiction?. International Journal of Productivity and Performance Management, 53(3), 245-260.

Rantanen, H., Kulmala, H. I., Lönnqvist, A., and Kujansivu, P. (2007). Performance measurement systems in the Finnish public sector, International Journal of Public Sector Management, Vol. 20 Issue: 5, pp. 415-433,

Reilly, R. (2010) Participatory case study. In: Mills, A., Durepos, G., Wiebe, E. (Eds.), Encyclopedia of Case Study Research. Sage Publications, Thousand Oaks, CA, pp. 658-661.

Ribeiro, J.A., and Scapens, R.W. (2006). Institutional theories in management accounting change: Contributions, issues and paths for development, Qualitative Research in Accounting \& Management, Vol. 3 Issue: 2, pp. 94-111

Sanderson, I. (2001). Performance management, evaluation and learning in 'modern' local government. Public administration, 79(2), 297-313.

Schleicher, D. J., Baumann, H. M., Sullivan, D. W., Levy, P. E., Hargrove, D. C., and BarrosRivera, B. A. (2018). Putting the system into performance management systems: A review and agenda for performance management research. Journal of management, 44(6), 2209-2245.

Song, M., and Meier, K. J. (2018). Citizen satisfaction and the kaleidoscope of government performance: How multiple stakeholders see government performance. Journal of Public Administration Research and Theory, 28(4), 489-505.

Taylor, J. (2014). Organizational Culture and the Paradox of Performance Management. Public Performance \& Management Review, 38:1, 7-22

Ter Bogt, H. J. (2008). Management Accounting Change and New Public Management in Local Government: A reassessment of ambitions and results. An institutionalist approach to accounting change in the Dutch public sector. Financial Accountability and Management, 24(3), pp. 209-241 
Ter Bogt, H. J., and van Helden, G. J. (2011). The role of consultant-researchers in the design and implementation process of a programme budget in a local government organization. Management Accounting Research, 22(1), 56-64.

Tilcsik, A. (2010). From ritual to reality: Demography, ideology, and decoupling in a postcommunist government agency. Academy of Management Journal, 53(6), 1474-1498.

Van Helden, I., Johnsen, A., and Vakkuri, J. (2008). Distinctive research patterns on public sector performance measurement of public administration and accounting disciplines. Public Management Review, 10:5, pp. 641-651.

Van Thiel, S. and Leeuw, F. L. (2002). The performance paradox in the public sector. Public Performance \& Management Review, 25(3), 267-281.

Yetano, A. (2013), What Drives the Institutionalization of Performance Measurement and Management in Local Government? Public Performance \& Management Review, 37:1, 59-86. 
Table 1. Descriptive statistics on the sample of municipalities.

\begin{tabular}{|l|c|c|c|}
\hline Municipality & A & B & C \\
\hline Size & Large & Small & Medium \\
\hline Personnel units (\#) & 1.870 & 243 & 979 \\
\hline Population (\#) & 211,210 & 44,573 & 122,367 \\
\hline $\begin{array}{l}\text { Territorial extension } \\
(\text { Km2) }\end{array}$ & 93.03 & 13.01 & 33.09 \\
\hline
\end{tabular}

Source: ISTAT (Istituto Nazionale di Statistica).

Table 2. Phases of the project, type of meetings and actors involved.

\begin{tabular}{|c|c|c|}
\hline Phase of the project & Data source & Actors involved \\
\hline $\begin{array}{l}\text { Phase 1. Municipality } \\
\text { engagement: presentation of } \\
\text { the project and its objectives }\end{array}$ & Plenary meetings at group level & $\begin{array}{ll}- & \text { Research group (i.e. } \\
\text { professional experts) } \\
\text { Agenzia per la Coesione } \\
\text { territoriale } \\
\text { - } \\
\text { Main sponsors (one for each } \\
\text { municipality - the mayor, the } \\
\text { general secretary or both) }\end{array}$ \\
\hline $\begin{array}{l}\text { Phase 2. PMS refinement. Ad } \\
\text { hoc presentation of the project } \\
\text { in each municipality, PMS } \\
\text { presentation with its indicators, } \\
\text { refinement and revision of } \\
\text { indicators and metrics, } \\
\text { definition of the main activities } \\
\text { for data collection }\end{array}$ & $\begin{array}{l}\text { Plenary meetings at municipality } \\
\text { level }\end{array}$ & $\begin{array}{ll}\text { - } & \text { Research group (i.e. } \\
\text { professional experts) } \\
\text { - } \\
\text { Main sponsors (one for each } \\
\text { municipality - the mayor, the } \\
\text { general secretary or both) } \\
\text { - Operational project leader for } \\
\text { each municipality }\end{array}$ \\
\hline $\begin{array}{l}\text { Phase 3. Data collection. } \\
\text { Involvement of ad hoc staff in } \\
\text { each municipality (following } \\
\text { the indicators included in the } \\
\text { PMS model), meetings to } \\
\text { further explain the project } \\
\end{array}$ & $\begin{array}{l}\text { Ad hoc meetings with some } \\
\text { representatives of the staff }\end{array}$ & $\begin{array}{ll}\text { - } & \text { Research group (i.e. } \\
\text { professional experts) } \\
\text { Middle ranking managers } \\
\text { from each municipality } \\
\text { depending on the service } \\
\text { under investigation } \\
\end{array}$ \\
\hline $\begin{array}{l}\text { Phase 4. PMS benchmarking: } \\
\text { presentation of data from the } \\
\text { PMS }\end{array}$ & Plenary meeting at group level & $\begin{array}{ll} & \text { Research group (i.e. } \\
\text { professional experts) } \\
\text { Agenzia per la Coesione } \\
\text { territoriale } \\
\text { - Main sponsors (one per each } \\
\text { municipality - the mayor, the } \\
\text { general secretary or both) }\end{array}$ \\
\hline
\end{tabular}


Table 3. Differences in PMS implementation patterns.

\begin{tabular}{|c|c|c|c|c|}
\hline $\begin{array}{c}\text { Municipality } \\
\text { label }\end{array}$ & $\begin{array}{c}\text { Power } \\
\text { dynamics }\end{array}$ & $\begin{array}{c}\text { Internal } \\
\text { communication }\end{array}$ & $\begin{array}{c}\text { Inclination to } \\
\text { learn }\end{array}$ & $\begin{array}{c}\text { Professional } \\
\text { experts }\end{array}$ \\
\hline $\begin{array}{c}\text { Formal } \\
\text { compliance } \\
(\text { Municipality A) }\end{array}$ & $\begin{array}{c}\text { Initially } \\
\text { centralised in } \\
\text { senior } \\
\text { administrative } \\
\text { roles, then } \\
\text { diminishing }\end{array}$ & $\begin{array}{l}\text { Mainly formal } \\
\text { and pushed by } \\
\text { professional } \\
\text { experts }\end{array}$ & Almost absent & Pushing role \\
\hline $\begin{array}{c}\text { Shared vision } \\
\text { (Municipality B) }\end{array}$ & $\begin{array}{l}\text { Distributed to } \\
\text { middle and } \\
\text { lower ranking } \\
\text { staff }\end{array}$ & $\begin{array}{l}\text { Highly visible, } \\
\text { formally and } \\
\text { informally }\end{array}$ & Distributed & Pulled role \\
\hline $\begin{array}{c}\text { Technical } \\
\text { oligarchy } \\
\text { (Municipality C) }\end{array}$ & $\begin{array}{l}\text { Centralised in } \\
\text { the specialised } \\
\text { group }\end{array}$ & $\begin{array}{l}\text { Mainly formal; } \\
\text { centralised in the } \\
\text { specialised } \\
\text { group }\end{array}$ & $\begin{array}{l}\text { Dependent on } \\
\text { the specific PMS } \\
\text { aspect and } \\
\text { centralised in the } \\
\text { specialised } \\
\text { group }\end{array}$ & $\begin{array}{l}\text { Pulled role only } \\
\text { if there was an } \\
\text { internal interest }\end{array}$ \\
\hline
\end{tabular}

